\title{
MYC and Transcription Elongation
}

\author{
Peter B. Rahl ${ }^{1}$ and Richard A. Young ${ }^{1,2}$ \\ ${ }^{1}$ Whitehead Institute for Biomedical Research, Cambridge, Massachusetts 02142 \\ ${ }^{2}$ Department of Biology, Massachusetts Institute of Technology, Cambridge, Massachusetts 02142 \\ Correspondence: young@wi.mit.edu
}

Most transcription factors specify the subset of genes that will be actively transcribed in the cell by stimulating transcription initiation at these genes, but MYC has a fundamentally different role. MYC binds E-box sites in the promoters of active genes and stimulates recruitment of the elongation factor P-TEFb and thus transcription elongation. Consequently, rather than specifying the set of genes that will be transcribed in any particular cell, MYC's predominant role is to increase the production of transcripts from active genes. This increase in the transcriptional output of the cell's existing gene expression program, called transcriptional amplification, has a profound effect on proliferation and other behaviors of a broad range of cells. Transcriptional amplification may reduce rate-limiting constraints for tumor cell proliferation and explain MYC's broad oncogenic activity among diverse tissues.

\section{TRANSCRIPTIONAL REGULATION}

$T^{\mathrm{s}}$ anscription factors bind specific DNA sequences and regulate the recruitment and activity of the transcription apparatus at genes (Ptashne and Gann 1997; Lee and Young 2013). The process of transcription consists of at least three steps: initiation, elongation, and termination (Fuda et al. 2009; Malik and Roeder 2010; Zhou et al. 2012). During initiation, the transcription apparatus, which consists of RNA polymerase II (Pol II) and various cofactors, is recruited to genes by transcription factors. A short transcript is produced by Pol II and pause factors typically induce pausing 20-50 bp downstream of the transcriptional start site. Elongation proceeds after the elongation factor $\mathrm{P}-\mathrm{TEFb}$, which consists of Cdk9 and cyclin T, is recruited, and phosphorylates the pause factors and Pol II. Transcription termination is stimulated by recognition of polyadenylation site sequences by factors associated with Pol II during elongation.

It has long been clear that specific transcription factors are responsible for recruiting Pol II to selected genes during transcription initiation, but evidence emerged in the last decade that argues for an additional level of control at the pause-release and/or elongation stage of transcription for a large number of genes (Fuda et al. 2009; Nechaev and Adelman 2011; Zhou et al. 2012; Conaway and Conaway 2013). For example, in various human cells, Pol II was found to occupy the promoters of the majority $(\sim 70 \%)$ of protein-coding genes, but full-length transcripts were detected at only a subset of these genes (Guenther et al. 2007). Similarly, a large fraction of Drosophila genes with roles in devel-

Editors: Chi V. Dang and Robert N. Eisenman

Additional Perspectives on MYC and the Pathway to Cancer available at www.perspectivesinmedicine.org

Copyright (C) 2014 Cold Spring Harbor Laboratory Press; all rights reserved; doi: 10.1101/cshperspect.a020990

Cite this article as Cold Spring Harb Perspect Med 2014;4:a020990 
opment were found to show evidence of transcription initiation, but not elongation (Muse et al. 2007; Zeitlinger et al. 2007). These results indicated that Pol II pausing occurs at many genes and suggested that pause control is an important step in global gene regulation.

Further investigation in mammalian cells revealed that Pol II initiates transcription bidirectionally and this divergent transcription produces short RNA species at active promoters, with full-length transcripts occurring predominantly across protein-coding genes following pause release (Core et al. 2008; Seila et al. 2008). Recent studies indicate that the RNAs produced by antisense transcription from promoters of protein-coding genes account for a large fraction of long noncoding RNA (lncRNA) species in mammalian cells (Sigova et al. 2013). Thus, Pol II molecules initiate divergent transcription at a large fraction of the genes in the genome, are subjected to pausing in both directions, and only a portion of the initiated Pol II molecules are released to produce the longer transcripts recognized as messenger RNAs (mRNAs) and lncRNAs. This further supports the idea that promoter-proximal pausing is a general feature of Pol II transcription and suggests that regulation of pause release influences both mRNA and lncRNA levels. Genome-wide studies show that the negative elongation factors NELF, DSIF, and Gdown 1 co-occupy most promoters with paused Pol II, and that the positive elongation factors P-TEFb and TFIIS, generally, control pause release at actively transcribed genes (Chao and Price 2001; Core et al. 2008; Gilchrist et al. 2010; Nechaev et al. 2010; Rahl et al. 2010; Cheng et al. 2012; Jishage et al. 2012). Thus, the control of promoter-proximal pausing and transcription elongation by these and other factors is important to global gene regulation.

\section{MYC and MAX}

MYC is a master regulator of cellular proliferation. Under normal physiologic conditions it connects growth-factor stimulation to cellular proliferation and cell-cycle progression. MYC coordinates these cellular events by forming a heterodimer with MAX and binding E-box sequences (Blackwood and Eisenman 1991). The MYC basic helix-loop-helix and leucine zipper (bHLH-LZ) domains, which are located at its carboxyl terminus, are responsible for dimerization with MAX and for DNA binding. MYC has multiple transcription activation domains (TADs) in its amino terminus that recruit transcription cofactors and chromatin regulators (McMahon et al. 1998, 2000; Park et al. 2001; Knoepfler et al. 2006). MAX also contains a bHLH-LZ domain, but lacks TADs. Similarly, other MAX dimerization partners such as Mnt and Mad contain bHLH-LZ domains to facilitate dimerization with MAX, but lack TADs (Ayer et al. 1993; Hurlin et al. 1997). MYC protein levels increase following growth-factor stimulation resulting in MYC binding to increasing amounts of the constitutively expressed MAX. MAX/MAX, Mad/MAX, and Mnt/ MAX dimers can also bind E-box sequences, and because these proteins lack transcriptional activation domains, these are thought to have a different transcriptional impact than MYC/ MAX heterodimers. MAX/MAX and Mad/ MAX binding to these sites may maintain an open chromatin structure at MYC/MAX binding sites that would allow for rapid activation of MYC-regulated genes following MYC protein induction (Ayer and Eisenman 1993; Baudino and Cleveland 2001). Consistent with this idea, MYC appears to require active chromatin modifications to bind the genome (Guccione et al. 2006; Nie et al. 2012; Soufi et al. 2012). There is evidence that RNA Pol II and other components of the transcription machinery can be loaded at promoters before MYC binding (Guccione et al. 2006; Lin et al. 2012; Nie et al. 2012), suggesting that MYC is not required to recruit the transcription apparatus to these promoters (see Sabò and Amati 2013).

\section{MYC Regulates Transcriptional Elongation}

Eberhardy and Farnham first reported that MYC regulated transcription of the human $C A D$ gene through a $\mathrm{P}-\mathrm{TEFb}$-dependent regulatory mechanism (Eberhardy and Farnham 2001; Eberhardy and Farnham 2002). RNA Pol 
II was found to be constitutively bound to the $C A D$ promoter, whereas full-length mRNA and RNA Pol II at the $3^{\prime}$ end of genes was detected only in S phase coincident with MYC occupancy. Furthermore, the E-box sites at the CAD promoter were dispensable for RNA Pol II recruitment. Thus, for the CAD gene, MYC binding was apparently required for transcription elongation, but not for RNA Pol II initiation.

MYC has been shown to interact with $\mathrm{P}$ $\mathrm{TEFb}$ subunits CycT1 and CDK9 in vitro and in vivo via Myc's TAD (Eberhardy and Farnham 2002; Kanazawa et al. 2003; Gargano et al. 2007; Rahl et al. 2010). The MYC and CycT1 interaction requires MYC Box I and MYC Box II in the TAD — the ability of these MYC domains to activate expression of a Gal4 transactivation assay correlated with their CycT1 binding (Eberhardy and Farnham 2002). Cyclin T1 interacts with MYC through its cyclin boxes, which is similar to this cyclin's binding mode to the acidic activation domains of other transcription factors such as CIITA and RelA (Kanazawa et al. 2000; Barboric et al. 2001). The MYC, CycT1, and Cdk9 complex isolated by Peterlin and colleagues can phosphorylate the RNA Pol II carboxy-terminal domain in vitro (Kanazawa et al. 2003). Furthermore, direct recruitment of P$\mathrm{TEFb}$ can substitute for Myc binding in CAD transcriptional activation (Eberhardy and Farnham 2002).

Studies of the control of the CCND2 gene also suggested a role for MYC in transcriptional steps subsequent to initiation. Eilers and colleagues found that MYC and FoxO regulate distinct steps in the transcription cycle at the CCND2 gene (Bouchard et al. 2004). Here the PI3K pathway, by regulating FoxO function, is responsible for preinitiation complex formation. Pol II and other components of the transcription initiation apparatus were found to be loaded at CCND2 in the absence of MYC activity.

Rahl et al. (2010) described multiple lines of evidence that MYC's dominant transcriptional role at most genes in embryonic stem cells is to regulate transcriptional pause release. For example, they found that reducing the levels of MYC caused a reduction in the levels of elongating Pol
II, but had little effect on the levels of promoterproximal Pol II in genome-wide chromatin immunoprecipitation-sequencing (ChIP-seq) assays. This is in contrast to the effect of reducing the levels of the pluripotency transcription factor Oct4, which reduced the levels of both promoter-proximal Pol II and elongating Pol II at its target genes. As described below, further studies revealed the significance of this mode of transcriptional regulation in cancer cells, in which elevated levels of MYC cause transcriptional amplification by increasing transcriptional pause release (Lin et al. 2012).

The control of transcriptional pause release by MYC plays a key role in control of the pluripotent ground state in murine embryonic stem cells (mESCs) (Marks et al. 2012). mESCs can be grown in two different conditions, referred to here as $2 \mathrm{i}$ and serum conditions, which produce two distinguishable cell states. When grown under $2 \mathrm{i}$ conditions, mESCs express low levels of c-Myc and show relatively low RNA Pol II pause release across the genome (a high ratio of initiating vs. elongating RNA Pol II). When grown in serum conditions, mESCs express relatively high levels of c-Myc and show higher levels of pause release across the genome. Thus, MYC's role in regulating transcriptional pause release appears to be key to the control of embryonic stem cell pluripotency.

\section{GENERAL TRANSCRIPTION ELONGATION CONTROL FACTORS}

The promoters of many genes in mammalian cells can be found occupied by Pol II together with the negative elongation factors DSIF, NELF, and Gdown 1 at positions located approximately $30-50$ bp downstream of the transcription start site (Fig. 1), also known as promoter-proximal pause sites (Fuda et al. 2009; Nechaev and Adelman 2011; Zhou et al. 2012). DSIF, which consists of Spt 4 and Spt5 subunits, was isolated as a factor that is essential for 5,6-dichloro-1-betaD-ribofuranosylbenzimidazole-induced transcriptional inhibition (Wada et al. 1998). NELF is a multisubunit complex that functions with DSIF to repress transcriptional elongation through binding Pol II in the promoter-proxi- 
Transcription factors recruit the transcription apparatus

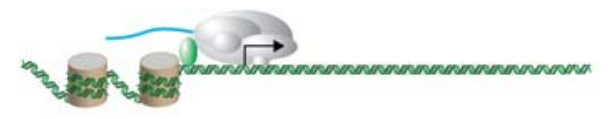

Promoter-proximal pausing occurs at most genes

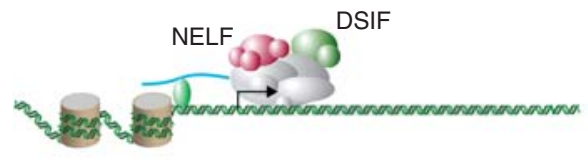

Other transcription factors, like MYC, recruit P-TEFb and other pause release factors to stimulate pause release

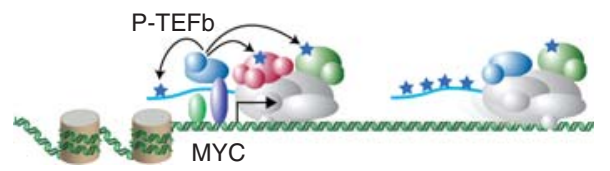

Figure 1. Key regulatory steps leading to transcriptional pause release. (Top) Transcription factors bind to specific DNA elements and recruit the transcription apparatus and Pol II to the transcription start site. (Middle) DSIF, NELF, and other pausing factors co-occupy regions near transcription start sites with Pol II. Pol II begins transcription from the initiation site, but pausing factors cause it to stall approximately $50 \mathrm{bp}$ downstream from the start site. (Bottom) Transcription factors, including MYC, and cofactors recruit pause-release factors such as $\mathrm{P}-\mathrm{TEFb}$, which phosphorylates the pausing factors, DSIF and NELF, and Pol II, leading to elongation. Additional pauserelease factors, including TFIIS and FACT, facilitate pause release and elongation. Adapted from Rahl et al. (2010) with permission from the author.

mal region (Yamaguchi et al. 1999). Gdown1 adds an additional layer of promoter-proximal negative regulation that plays an important role in Mediator-dependent gene activation ( $\mathrm{Hu}$ et al. 2006; Cheng et al. 2012; Jishage et al. 2012). Thus, Pol II occupies pause sites at a large population of genes together with this set of negative elongation factors, and the functions of these negative factors must be overcome to allow full-length transcript production.

Pause release and processive transcript elongation requires the recruitment of pause-release factors, which include P-TEFb, TFIIS, and FACT (Fuda et al. 2009; Nechaev and Adelman 2011; Zhou et al. 2012). P-TEFb phosphorylates multiple key substrates important for stimulat- ing pause release including DSIF, NELF, and the carboxy-terminal heptapeptide repeat domain of Pol II. TFIIS activity counteracts backtracking and arrests (Adelman et al. 2005). The FACT complex aids transcript elongation by remodeling nucleosomes to allow for Pol II transit through the gene (Orphanides et al. 1998; Winkler and Luger 2011). It is the recruitment of these factors by various transcriptional regulators that therefore plays a key role in effecting the gene expression program of cells.

\section{RECRUITMENT OF TRANSCRIPTION ELONGATION CONTROL FACTORS}

Transcription elongation is regulated by at least three types of protein complexes: the Mediator complex, a protein associated with both Mediator and acetylated nucleosomes called BRD4, and a variety of DNA-binding transcription factors.

The Mediator coactivator complex functions as a molecular switch capable of regulating both the initiation and elongation stages of transcription. DNA-binding transcription factors bind directly to the Mediator complex, which, in turn, binds to the transcriptional machinery (Malik and Roeder 2010; Meyer et al. 2010; Knuesel and Taatjes 2011). The human Mediator complex is approximately $1.2 \mathrm{mDa}$ and consists of about 30 subunits. Mediator coordinates transcription and higher-ordered chromatin structure through interactions with numerous transcription factors, cofactors, and Pol II. A domain in the MED26 subunit has been identified that can interact with either the general initiation factor TFIID or P-TEFb, and can contribute alternately to initiation and pause release (Takahashi et al. 2011). The MED23 subunit can also contribute to $\mathrm{P}-\mathrm{TEFb}$ recruitment and pause release (Wang et al. 2013). This is consistent with evidence that Mediator is required for activator-dependent stimulation of RNA Pol II transcription when RNA Pol II is associated with the negative elongation factor Gdown1 in in vitro transcription assays $(\mathrm{Hu}$ et al. 2006). Furthermore, Mediator can be copurified with BRD4 and co-occupies promoters genome-wide with BRD4 (Jiang et al. 1998; 
Loven et al. 2013; Whyte et al. 2013), and BRD4 is involved in $\mathrm{P}-\mathrm{TEFb}$ recruitment, as described in more detail below. These studies argue that Mediator plays an important role in coordinating initiation and elongation.

The BET bromodomain protein BRD4, which contains two bromodomains that interact with acetylated lysines in the nucleosomal histones of active promoter regions, binds the active form of P-TEFb and thereby stimulates pause release (Jang et al. 2005; Yang et al. 2005; Krueger et al. 2010). BRD4 has been shown to interact with the transcription factors MYC/MAX, c-Jun, AP2, YY1, p53, C/EBP $\alpha$, and $\mathrm{C} / \mathrm{EBP} \beta$, suggesting that all these factors may influence elongation (Wu et al. 2013). Interestingly, Brd4 interacts with MYC/MAX heterodimers, but not MAX or MXD/MAX complexes, suggesting that a structural feature present on MYC but not on the structurally similar MAX or Mad accounts for the interaction with BRD4 (Wu et al. 2013). BRD4 thus serves as an adaptor protein to link active P$\mathrm{TEFb}$ complex to transcriptional activators and chromatin to coordinate pause release.

Several families of sequence-specific transcription factors can recruit pause-release factors and may function through postinitiation mechanisms. Basic helix-loop-helix transcription factors including MYC, nuclear hormone receptors such as $E R \alpha$, and cytokine-responsive factors including NFKB and CIITA have all been shown to recruit $\mathrm{P}-\mathrm{TEFb}$ to control postinitiation regulation at regulated genes (Peterlin and Price 2006). Aire induces expression of peripheral tissue antigens in thymic epithelial cells via pause release in which Aire deficiency has been shown to have little effect on initiation, but results in a block in elongation (Oven et al. 2007; Giraud et al. 2012). The transcription factor p53 can regulate transcription through postinitiation mechanisms by modulating Mediator structure and function (Donner et al. 2010).

\section{MYC Oncogenic Activity Alters Cellular Gene Expression Programs}

MYC is one of the most potent oncogenes and possesses broad oncogenic activity in a wide range of human cancers. MYC's primary mode of deregulation in cancer is through altered levels of MYC protein, resulting in deregulated MYC activity. A broad spectrum of cellular roles has been attributed to MYC in cancer, including regulation of cell cycle, cell proliferation, response to growth factors, ribosome biogenesis, protein synthesis, cell adhesion and cytoskeleton, angiogenesis, metabolic pathways, apoptosis, DNA replication, mRNA capping, and chromatin structure (Amati et al. 1998, 2001; Facchini and Penn 1998; Nilsson and Cleveland 2003; Hurlin and Dezfouli 2004; Secombe et al. 2004; Gallant 2005; Bernard and Eilers 2006; Dang et al. 2006, 2009; Kuttler and Mai 2006; Meyer et al. 2006; Cowling and Cole 2007, 2010; Lebofsky and Walter 2007; Nieminen et al. 2007; Shchors and Evan 2007; Sutphin et al. 2007; Cole and Cowling 2008; Dai and Lu 2008; Eilers and Eisenman 2008; Hoffman and Liebermann 2008; Meyer and Penn 2008; Prochownik 2008; Herold et al. 2009; Lin et al. 2009; Ruggero 2009; Singh and Dalton 2009; Dang 2010; van Riggelen et al. 2010; Hanahan and Weinberg 2011; Peterson and Ayer 2012; Conacci-Sorrell et al. 2013). How does oncogenic MYC activity produce these broad effects?

Two models have been proposed to explain the impact of oncogenic MYC activity on the cellular gene expression program. Distinct thresholds of MYC expression are required for increasing proliferation and apoptosis in vivo (Murphy et al. 2008). In their preview of this study, Freie and Eisenman (2008) proposed two models to explain how increased MYClevels can account for these cellular effects. In the first model, MYC binds and activates a new set of genes when expressed at increased levels. In the second model, MYC binds more of the genes it occupies when expressed at lower levels, whereby increased binding results in increased expression of the same set of genes.

It has been widely assumed that MYC, when expressed at high levels, binds and activates a new set of genes. Numerous gene expression studies have identified specific sets of genes whose expression levels are altered by changes in MYC levels; these so-called MYC targets might thus explain MYC's role in cancer (Schuh- 
macher et al. 2001; Schlosser et al. 2005; Dang et al. 2006; Kim et al. 2006; Ji et al. 2011). However, it is evident that these "MYC signatures" tend to vary greatly across cell types (Chandriani et al. 2009), which has made it difficult to ascribe MYC's oncogenic properties to a specific set of target genes.

\section{Transcriptional Amplification}

MYC's dominant transcriptional role in embryonic stem cells is to regulate transcriptional pause release genome-wide (Rahl et al., 2010), but it was not clear from this study how exceptionally high levels (oncogenic levels) of MYC might impact tumor cells. The MYC-inducible P493-6 B cell lymphoma cell line model and various other MYC-dependent human cancer cell lines were recently used to study this issue (Lin et al. 2012). The effect of elevated levels of MYC on its occupancy was analyzed using ChIP-seq analysis. In general, MYC occupied the core promoter of active genes together with RNA Pol II. Increasing MYC protein levels 28-fold in P493-6 cells had little effect on the total number of genes bound by MYC or the number of genes that were actively transcribed. Rather, the predominant effect on MYC occupancy was increased levels of MYC binding at the promoters of the same set of active genes. Increased levels of MYC also caused it to occupy the enhancers of actively transcribed genes. MYC occupied lower affinity E-box sequences at core promoters and enhancers when expressed at high levels (Fig. 2). Similar results were obtained with human cancer cell lines overexpressing MYC. The predominant effect of increased MYC occupancy at genes was increased transcriptional pause release. Increased MYC occupancy led to increased P-TEFb occupancy, increased levels of RNAPII Serine 2 (a modification associated with elongation), increased levels of elongating RNAPII, and increased levels of mRNA for the active gene expression program. Thus, the primary effect of elevated levels of MYC is transcriptional amplification: the production of increased levels of transcripts within the cell's gene expression program (Fig. 3).
MYC acts as a transcriptional amplifier in nonpathological settings as well. By studying MYC activity in murine lymphocyte activation and embryonic stem cells, Levens and colleagues found that MYC does not specifically activate or repress genes, rather it is a nonlinear amplifier of most actively transcribed genes (Nie et al. 2012). For example, RNA Pol II loading at promoters of resting and activated $\mathrm{B}$ cells is highly similar. MYC expression in activated B cells simply elevates the expression level of genes already expressed. Therefore, MYC is an amplifier under normal physiologic conditions and cancer exploits this function through deregulating its activity (see Levens 2013).

MYC overexpression consistently results in global transcriptional amplification with widespread increases in transcripts per cell following increases in MYC levels (Loven et al. 2012). Importantly, however, a prolonged increase of MYC activity can lead to repression of certain genes as secondary effects begin to occur. For example, increased expression of repressors, including miRNAs and Polycomb proteins, can lead to repression of some genes (Neri et al. 2012). Thus, the net effect of global transcriptional amplification can ultimately cause repression of certain genes.

Transcriptional amplification of the cell's gene expression program can account for Myc's diverse roles in cancer and explain why MYC plays a critical role in tumorigenesis in a wide variety of human tissues. MYC signatures vary greatly across multiple cell types (Chandriani et al. 2009). The transcriptional amplification model provides an explanation for this variation. The set of genes whose expression is altered by MYC should, in fact, be different in different cell types, as oncogenic MYC will amplify each cell's inherent gene expression program and not an MYC-specific program.

MYC's broad oncogenic activity suggests that it can reduce different rate-limiting constraints for cellular proliferation in different cells (Vita and Henriksson 2006). In this model of transcription amplification, genes rate limiting for growth should be amplified provided they are transcriptionally active before MYC elevation. For example, MYC-mediated tran- 
MYC and Transcription Elongation

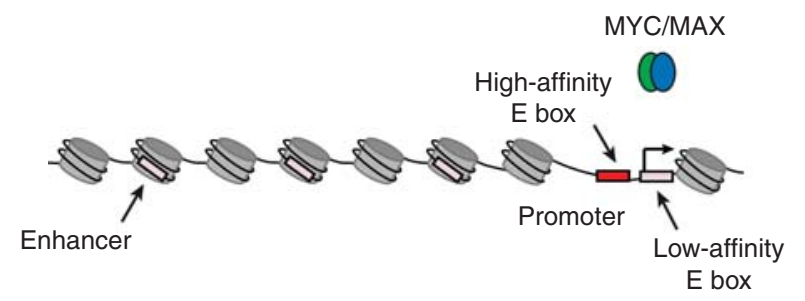

Low MYC

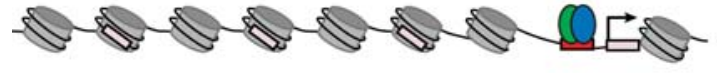

High MYC
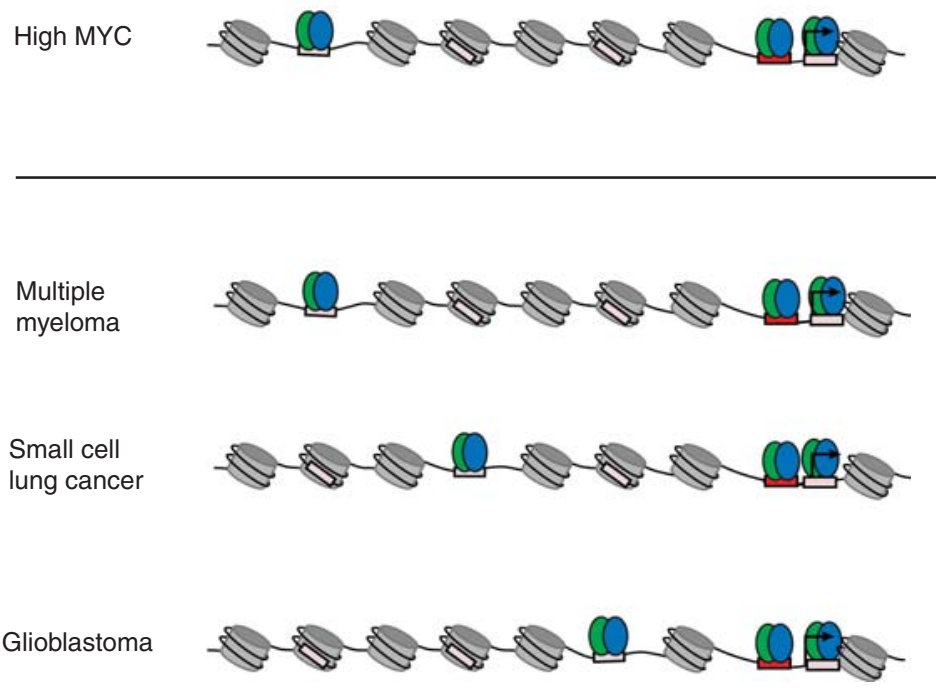

Figure 2. Elevated levels of MYC leads to altered genome-wide occupancy. (Top) When expressed at low levels, MYC/MAX dimers occupy high-affinity E-box sites in the genome, which are generally located near transcriptional start sites. When expressed at elevated levels, MYC/MAX dimers saturate high-affinity E-box sites and occupy lower affinity binding sites near transcription start sites and at enhancer regions. (Bottom) When overexpressed in different cancer types, MYC/MAX dimers bind low-affinity sites at enhancers. Because many enhancers are used in a tissue-specific manner, open chromatin regions with low-affinity binding sites can vary between cancer types, thus leading to different MYC/MAX binding profiles at enhancers in different cancer types.

scriptional amplification of ribosomal subunits could increase translational capacity (Arabi et al. 2005; Grandori et al. 2005; Grewal et al. 2005; Dai and $\mathrm{Lu}$ 2008). For cellular functions that are limiting for the growth of tumorigenic cells such as translational capacity and aerobic energy metabolism, an increase in this machinery would provide a mechanism to explain how elevated MYC levels contribute to tumorigenesis (Ruggero et al. 2004; Dang et al. 2009; Feng and Levine 2010; Vander Heiden et al. 2010; Hanahan and Weinberg 2011; Bayley and Devilee 2012). It is also possible that the increase in essentially all components of the gene expression program provides cells with an advantage when adapting to the multiple mutated pathways that characterize most tumor cells.

There has been substantial progress in our understanding of MYC-dependent transcriptional control across the genome and how it influences cell state. N-MYC and L-MYC are also powerful oncogenes that function as transcription factors, although less is known about their transcriptional regulatory circuitry. Future studies of N-MYC and L-MYC function should 
P.B. Rahl and R.A. Young

Low MYC

High MYC

Enhanced occupancy of control regions and increased Pol II pause release at actively transcribed genes

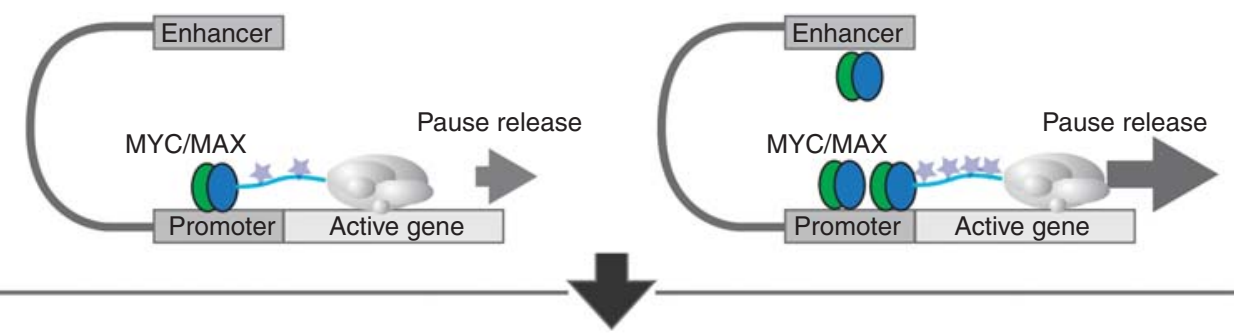

Transcriptional amplification of genes within the cell's existing gene expression program, specified by other transcription factors

RNA
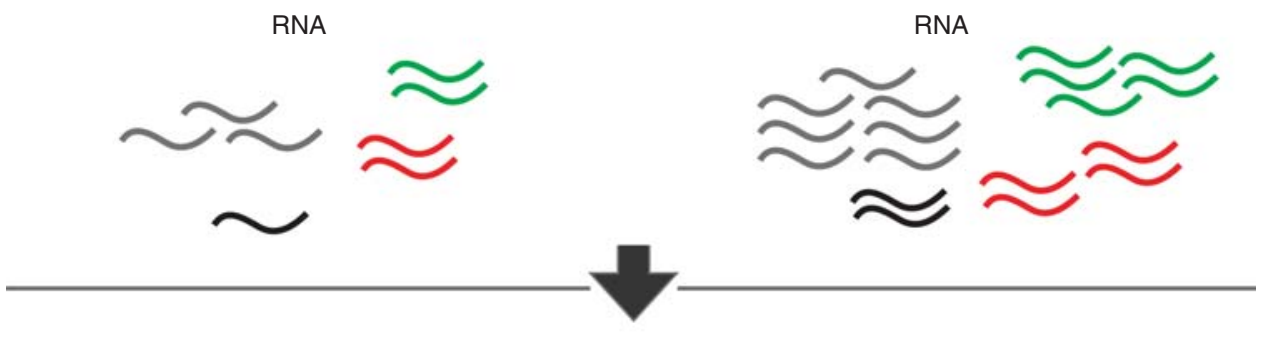

Reduction of rate-limiting constraints for tumor cell growth and proliferation
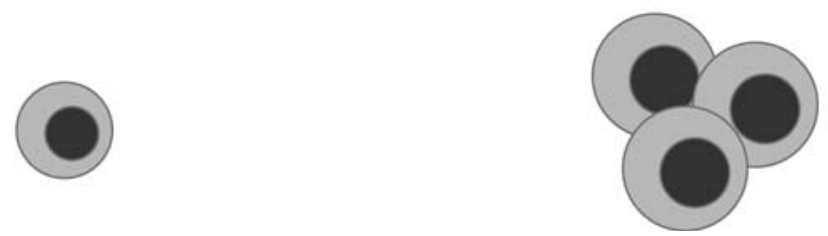

Figure 3. Elevated levels of MYC leads to transcriptional amplification. (Top) High levels of MYC lead to enhanced occupancy at transcriptional start sites and enhancer elements and increased Pol II pause release. (Middle) High levels of MYC lead to transcriptional amplification of the actively transcribed genes in the cell. The cell's existing gene expression program is specified by other transcription factors. (Bottom) The amplification of the gene expression program can reduce rate-limiting constraints for cell growth and proliferation. (From Lin et al. 2012; adapted, with permission, from the author.)

provide important insight into the similarities or differences among the MYC family regulatory circuitry. MYC appears to be a broader-acting oncogene with tumorigenic activity in diverse tissues, whereas N-MYC and L-MYC are often more restricted in the tissues they transform. Despite this difference, which may be largely due to tissue-specific expression, there are likely to be many mechanistic similarities among the MYC family as they are all powerful oncogenes. Such similarity is suggested by different subclasses of medulloblastoma that appear to acti- vate MYC family transcription factors through any means necessary: MYC amplification, MYCN amplification, MYCL1 amplification, or deregulated upstream signaling pathways including Wnt (Northcott et al. 2012; Roussel and Robinson 2013).

\section{ACKNOWLEDGMENTS}

We thank our funding sources (National Institutes of Health grants HG002668 and CA146445) and the editors Robert Eisenman 
MYC and Transcription Elongation

and Chi Dang for their comments on the manuscript.

\section{REFERENCES}

${ }^{*}$ Reference is also in this collection.

Adelman K, Marr MT, Werner J, Saunders A, Ni Z, Andrulis ED, Lis JT. 2005. Efficient release from promoter-proximal stall sites requires transcript cleavage factor TFIIS. Mol Cell 17: 103-112.

Amati B, Alevizopoulos K, Vlach J. 1998. Myc and the cell cycle. Front Biosci 3: d250-d268.

Amati B, Frank SR, Donjerkovic D, Taubert S. 2001. Function of the c-Myc oncoprotein in chromatin remodeling and transcription. Biochim Biophys Acta 1471: M135M145.

Arabi A, Wu S, Ridderstrale K, Bierhoff H, Shiue C, Fatyol K, Fahlen S, Hydbring P, Soderberg O, Grummt I, et al. 2005. c-Myc associates with ribosomal DNA and activates RNA polymerase I transcription. Nat Cell Biol 7: 303-310.

Ayer DE, Eisenman RN. 1993. A switch from Myc:Max to Mad:Max heterocomplexes accompanies monocyte/ macrophage differentiation. Genes Dev 7: 2110-2119.

Ayer DE, Kretzner L, Eisenman RN. 1993. Mad: A heterodimeric partner for Max that antagonizes Myc transcriptional activity. Cell 72: 211-222.

Barboric M, Nissen RM, Kanazawa S, Jabrane-Ferrat N, Peterlin BM. 2001. NF- $\mathrm{\kappa B}$ binds P-TEFb to stimulate transcriptional elongation by RNA polymerase II. Mol Cell 8: 327-337.

Baudino TA, Cleveland JL. 2001. The Max network gone mad. Mol Cell Biol 21: 691-702.

Bayley JP, Devilee P. 2012. The Warburg effect in 2012. Curr Opin Oncol 24: 62-67.

Bernard S, Eilers M. 2006. Control of cell proliferation and growth by Myc proteins. Results Probl Cell Differ 42: 329342.

Blackwood EM, Eisenman RN. 1991. Max: A helix-loop-helix zipper protein that forms a sequence-specific DNAbinding complex with Myc. Science 251: 1211-1217.

Bouchard C, Marquardt J, Bras A, Medema RH, Eilers M. 2004. Myc-induced proliferation and transformation require Akt-mediated phosphorylation of FoxO proteins. EMBO J 23: 2830-2840.

Chandriani S, Frengen E, Cowling VH, Pendergrass SA, Perou CM, Whitfield ML, Cole MD. 2009. A core MYC gene expression signature is prominent in basal-like breast cancer but only partially overlaps the core serum response. PLoS ONE 4: e6693.

Chao SH, Price DH. 2001. Flavopiridol inactivates P-TEFb and blocks most RNA polymerase II transcription in vivo. J Biol Chem 276: 31793-31799.

Cheng B, Li T, Rahl PB, Adamson TE, Loudas NB, Guo J, Varzavand K, Cooper JJ, Hu X, Gnatt A, et al. 2012. Functional association of Gdown1 with RNA polymerase II poised on human genes. Mol Cell 45: 38-50.

Cole MD, Cowling VH. 2008. Transcription-independent functions of MYC: Regulation of translation and DNA replication. Nat Rev Mol Cell Biol 9: 810-815.
* Conacci-Sorrell M, McFerrin L, Eisenman RN. 2013. An overview of MYC and its interactome. Cold Spring Harb Perspect Med doi: 10.1101/cshperspect.a014357.

Conaway RC, Conaway JW. 2013. The Mediator complex and transcription elongation. Biochim Biophys Acta 1829: 69-75.

Core LJ, Waterfall JJ, Lis JT. 2008. Nascent RNA sequencing reveals widespread pausing and divergent initiation at human promoters. Science 322: 1845-1848.

Cowling VH, Cole MD. 2007. Turning the tables: Myc activates Wnt in breast cancer. Cell Cycle 6: 2625-2627.

Cowling VH, Cole MD. 2010. Myc regulation of mRNA cap methylation. Genes Cancer 1: 576-579.

Dai MS, Lu H. 2008. Crosstalk between c-Myc and ribosome in ribosomal biogenesis and cancer. J Cell Biochem 105: 670-677.

Dang CV. 2010. Rethinking the Warburg effect with Myc micromanaging glutamine metabolism. Cancer Res 70: 859-862.

Dang CV, O’Donnell KA, Zeller KI, Nguyen T, Osthus RC, Li F. 2006. The c-Myc target gene network. Semin Cancer Biol 16: 253-264.

Dang CV, Le A, Gao P. 2009. MYC-induced cancer cell energy metabolism and therapeutic opportunities. Clin Cancer Res 15: 6479-6483.

Donner AJ, Ebmeier CC, Taatjes DJ, Espinosa JM. 2010. CDK8 is a positive regulator of transcriptional elongation within the serum response network. Nat Struct Mol Biol 17: 194-201.

Eberhardy SR, Farnham PJ. 2001. c-Myc mediates activation of the cad promoter via a post-RNA polymerase II recruitment mechanism. J Biol Chem 276: 48562-48571.

Eberhardy SR, Farnham PJ. 2002. Myc recruits P-TEFb to mediate the final step in the transcriptional activation of the cad promoter. J Biol Chem 277: 40156-40162.

Eilers M, Eisenman RN. 2008. Myc's broad reach. Genes Dev 22: 2755-2766.

Facchini LM, Penn LZ. 1998. The molecular role of Myc in growth and transformation: Recent discoveries lead to new insights. FASEB J 12: 633-651.

Feng Z, Levine AJ. 2010. The regulation of energy metabolism and the IGF-1/mTOR pathways by the $\mathrm{p} 53$ protein. Trends Cell Biol 20: 427-434.

Freie BW, Eisenman RN. 2008. Ratcheting Myc. Cancer Cell 14: $425-426$.

Fuda NJ, Ardehali MB, Lis JT. 2009. Defining mechanisms that regulate RNA polymerase II transcription in vivo. Nature 461: 186-192.

Gallant P. 2005. Myc, cell competition, and compensatory proliferation. Cancer Res 65: 6485-6487.

Gargano B, Amente S, Majello B, Lania L. 2007. P-TEFb is a crucial co-factor for Myc transactivation. Cell Cycle 6: 2031-2037.

Gilchrist DA, Dos Santos G, Fargo DC, Xie B, Gao Y, Li L, Adelman K. 2010. Pausing of RNA polymerase II disrupts DNA-specified nucleosome organization to enable precise gene regulation. Cell 143: 540-551.

Giraud M, Yoshida H, Abramson J, Rahl PB, Young RA, Mathis D, Benoist C. 2012. Aire unleashes stalled RNA 
P.B. Rahl and R.A. Young

polymerase to induce ectopic gene expression in thymic epithelial cells. Proc Natl Acad Sci 109: 535-540.

Grandori C, Gomez-Roman N, Felton-Edkins ZA, Ngouenet C, Galloway DA, Eisenman RN, White RJ. 2005. cMyc binds to human ribosomal DNA and stimulates transcription of rRNA genes by RNA polymerase I. Nat Cell Biol 7: 311-318.

Grewal SS, Li L, Orian A, Eisenman RN, Edgar BA. 2005. Myc-dependent regulation of ribosomal RNA synthesis during Drosophila development. Nat Cell Biol 7: 295302.

Guccione E, Martinato F, Finocchiaro G, Luzi L, Tizzoni L, Dall' Olio V, Zardo G, Nervi C, Bernard L, Amati B. 2006. Myc-binding-site recognition in the human genome is determined by chromatin context. Nat Cell Biol 8: $764-$ 770 .

Guenther MG, Levine SS, Boyer LA, Jaenisch R, Young RA. 2007. A chromatin landmark and transcription initiation at most promoters in human cells. Cell 130: 77-88.

Hanahan D, Weinberg RA. 2011. Hallmarks of cancer: The next generation. Cell 144: 646-674.

Herold S, Herkert B, Eilers M. 2009. Facilitating replication under stress: An oncogenic function of MYC? Nat Rev Cancer 9: 441-444.

Hoffman B, Liebermann DA. 2008. Apoptotic signaling by c-MYC. Oncogene 27: 6462-6472.

Hu X, Malik S, Negroiu CC, Hubbard K, Velalar CN, Hampton B, Grosu D, Catalano J, Roeder RG, Gnatt A. 2006. A Mediator-responsive form of metazoan RNA polymerase II. Proc Natl Acad Sci 103: 9506-9511.

Hurlin PJ, Dezfouli S. 2004. Functions of myc:max in the control of cell proliferation and tumorigenesis. Int Rev Cytol 238: 183-226.

Hurlin PJ, Queva C, Eisenman RN. 1997. Mnt, a novel Maxinteracting protein is coexpressed with Myc in proliferating cells and mediates repression at Myc binding sites. Genes Dev 11: 44-58.

Jang MK, Mochizuki K, Zhou M, Jeong HS, Brady JN, Ozato K. 2005. The bromodomain protein Brd4 is a positive regulatory component of $\mathrm{P}-\mathrm{TEFb}$ and stimulates RNA polymerase II-dependent transcription. Mol Cell 19: 523-534.

Ji H, Wu G, Zhan X, Nolan A, Koh C, De Marzo A, Doan HM, Fan J, Cheadle C, Fallahi M, et al. 2011. Cell-type independent MYC target genes reveal a primordial signature involved in biomass accumulation. PLOS ONE 6: e26057.

Jiang YW, Veschambre P, Erdjument-Bromage H, Tempst P, Conaway JW, Conaway RC, Kornberg RD. 1998. Mammalian mediator of transcriptional regulation and its possible role as an end-point of signal transduction pathways. Proc Natl Acad Sci 95: 8538-8543.

Jishage M, Malik S, Wagner U, Uberheide B, Ishihama Y, Hu X, Chait BT, Gnatt A, Ren B, Roeder RG. 2012. Transcriptional regulation by Pol $\mathrm{II}(\mathrm{G})$ involving mediator and competitive interactions of Gdown1 and TFIIF with Pol II. Mol Cell 45: 51-63.

Kanazawa S, Okamoto T, Peterlin BM. 2000. Tat competes with CIITA for the binding to P-TEFb and blocks the expression of MHC class II genes in HIV infection. Immunity 12: 61-70.
Kanazawa S, Soucek L, Evan G, Okamoto T, Peterlin BM. 2003. c-Myc recruits P-TEFb for transcription, cellular proliferation and apoptosis. Oncogene 22: 5707-5711.

Kim YH, Girard L, Giacomini CP, Wang P, Hernandez-Boussard T, Tibshirani R, Minna JD, Pollack JR. 2006. Combined microarray analysis of small cell lung cancer reveals altered apoptotic balance and distinct expression signatures of MYC family gene amplification. Oncogene 25: $130-138$.

Knoepfler PS, Zhang XY, Cheng PF, Gafken PR, McMahon SB, Eisenman RN. 2006. Myc influences global chromatin structure. EMBO J 25: 2723-2734.

Knuesel MT, Taatjes DJ. 2011. Mediator and post-recruitment regulation of RNA polymerase II. Transcription 2: $28-31$

Krueger BJ, Varzavand K, Cooper JJ, Price DH. 2010. The mechanism of release of P-TEFb and HEXIM1 from the 7SK snRNP by viral and cellular activators includes a conformational change in 7SK. PLoS ONE 5: e12335.

Kuttler F, Mai S. 2006. c-Myc, genomic instability and disease. Genome Dyn 1: 171-190.

Lebofsky R, Walter JC. 2007. New Myc-anisms for DNA replication and tumorigenesis? Cancer Cell 12: 102-103.

Lee TI, Young RA. 2013. Transcriptional regulation and its misregulation in disease. Cell 152: 1237-1251.

* Levens D. 2013. Cellular MYCro economics: Balancing MYC function with MYC expression. Cold Spring Harb Perspect Med 5: a014233.

Lin CJ, Malina A, Pelletier J. 2009. c-Myc and eIF4F constitute a feedforward loop that regulates cell growth: Implications for anticancer therapy. Cancer Res 69: 74917494.

Lin CY, Loven J, Rahl PB, Paranal RM, Burge CB, Bradner JE, Lee TI, Young RA. 2012. Transcriptional amplification in tumor cells with elevated c-Myc. Cell 151: 56-67.

Loven J, Orlando DA, Sigova AA, Lin CY, Rahl PB, Burge CB, Levens DL, Lee TI, Young RA. 2012. Revisiting global gene expression analysis. Cell 151: 476-482.

Loven J, Hoke HA, Lin CY, Lau A, Orlando DA, Vakoc CR, Bradner JE, Lee TI, Young RA. 2013. Selective inhibition of tumor oncogenes by disruption of super-enhancers. Cell 153: 320-334.

Malik S, Roeder RG. 2010. The metazoan Mediator co-activator complex as an integrative hub for transcriptional regulation. Nat Rev Genet 11: 761-772.

Marks H, Kalkan T, Menafra R, Denissov S, Jones K, Hofemeister H, Nichols J, Kranz A, Stewart AF, Smith A, et al. 2012. The transcriptional and epigenomic foundations of ground state pluripotency. Cell 149: 590-604.

McMahon SB, Van Buskirk HA, Dugan KA, Copeland TD, Cole MD. 1998. The novel ATM-related protein TRRAP is an essential cofactor for the c-Myc and E2F oncoproteins. Cell 94: 363-374.

McMahon SB, Wood MA, Cole MD. 2000. The essential cofactor TRRAP recruits the histone acetyltransferase hGCN5 to c-Myc. Mol Cell Biol 20: 556-562.

Meyer N, Penn LZ. 2008. Reflecting on 25 years with MYC. Nat Rev Cancer 8: 976-990.

Meyer N, Kim SS, Penn LZ. 2006. The Oscar-worthy role of Myc in apoptosis. Semin Cancer Biol 16: 275-287. 
Meyer KD, Lin SC, Bernecky C, Gao Y, Taatjes DJ. 2010. p53 activates transcription by directing structural shifts in Mediator. Nat Struct Mol Biol 17: 753-760.

Murphy DJ, Junttila MR, Pouyet L, Karnezis A, Shchors K, Bui DA, Brown-Swigart L, Johnson L, Evan GI. 2008. Distinct thresholds govern Myc's biological output in vivo. Cancer Cell 14: 447-457.

Muse GW, Gilchrist DA, Nechaev S, Shah R, Parker JS, Grissom SF, Zeitlinger J, Adelman K. 2007. RNA polymerase is poised for activation across the genome. Nat Genet 39: 1507-1511.

Nechaev S, Adelman K. 2011. Pol II waiting in the starting gates: Regulating the transition from transcription initiation into productive elongation. Biochim Biophys Acto 1809: 34-45.

Nechaev S, Fargo DC, dos Santos G, Liu L, Gao Y, Adelman K. 2010. Global analysis of short RNAs reveals widespread promoter-proximal stalling and arrest of Pol II in Drosophila. Science 327: 335-338.

Neri F, Zippo A, Krepelova A, Cherubini A, Rocchigiani M, Oliviero S. 2012. Myc regulates the transcription of the PRC2 gene to control the expression of developmental genes in embryonic stem cells. Mol Cell Biol 32: 840-851.

Nie Z, Hu G, Wei G, Cui K, Yamane A, Resch W, Wang R, Green DR, Tessarollo L, Casellas R, et al. 2012. c-Myc is a universal amplifier of expressed genes in lymphocytes and embryonic stem cells. Cell 151: 68-79.

Nieminen AI, Partanen JI, Klefstrom J. 2007. c-Myc blazing a trail of death: Coupling of the mitochondrial and death receptor apoptosis pathways by c-Myc. Cell Cycle 6: 2464-2472.

Nilsson JA, Cleveland JL. 2003. Myc pathways provoking cell suicide and cancer. Oncogene 22: 9007-9021.

Northcott PA, Shih DJ, Peacock J, Garzia L, Morrissy AS, Zichner T, Stutz AM, Korshunov A, Reimand J, Schumacher SE, et al. 2012. Subgroup-specific structural variation across 1,000 medulloblastoma genomes. Nature 488: 49-56.

Orphanides G, LeRoy G, Chang CH, Luse DS, Reinberg D. 1998. FACT, a factor that facilitates transcript elongation through nucleosomes. Cell 92: 105-116.

Oven I, Brdickova N, Kohoutek J, Vaupotic T, Narat M, Peterlin BM. 2007. AIRE recruits P-TEFb for transcriptional elongation of target genes in medullary thymic epithelial cells. Mol Cell Biol 27: 8815-8823.

Park J, Kunjibettu S, McMahon SB, Cole MD. 2001. The ATM-related domain of TRRAP is required for histone acetyltransferase recruitment and Myc-dependent oncogenesis. Genes Dev 15: 1619-1624.

Peterlin BM, Price DH. 2006. Controlling the elongation phase of transcription with P-TEFb. Mol Cell 23: 297305.

Peterson CW, Ayer DE. 2012. An extended Myc network contributes to glucose homeostasis in cancer and diabetes. Front Biosci 17: 2206-2223.

Prochownik EV. 2008. c-Myc: Linking transformation and genomic instability. Curr Mol Med 8: 446-458.

Ptashne M, Gann A. 1997. Transcriptional activation by recruitment. Nature 386: 569-577.
Rahl PB, Lin CY, Seila AC, Flynn RA, McCuine S, Burge CB, Sharp PA, Young RA. 2010. c-Myc regulates transcriptional pause release. Cell 141: 432-445.

* Roussel MF, Robinson GW. 2013. Role of MYC in medulloblastoma. Cold Spring Harb Perspect Med doi: 10.1101/ cshperspect.a014308.

Ruggero D. 2009. The role of Myc-induced protein synthesis in cancer. Cancer Res 69: 8839-8843.

Ruggero D, Montanaro L, Ma L, Xu W, Londei P, CordonCardo C, Pandolfi PP. 2004. The translation factor eIF-4E promotes tumor formation and cooperates with c-Myc in lymphomagenesis. Nat Med 10: 484-486.

* Sabò A, Amati B. 2013. Genome recognition by Myc. Cold Spring Harb Perspect Med doi: 10.1101/cshperspect. a014191.

Schlosser I, Holzel M, Hoffmann R, Burtscher H, Kohlhuber F, Schuhmacher M, Chapman R, Weidle UH, Eick D. 2005. Dissection of transcriptional programmes in response to serum and c-Myc in a human B-cell line. Oncogene 24: 520-524.

Schuhmacher M, Kohlhuber F, Holzel M, Kaiser C, Burtscher H, Jarsch M, Bornkamm GW, Laux G, Polack A, Weidle UH, et al. 2001. The transcriptional program of a human B cell line in response to Myc. Nucleic Acids Res 29: $397-406$.

Secombe J, Pierce SB, Eisenman RN. 2004. Myc: Aweapon of mass destruction. Cell 117: 153-156.

Seila AC, Calabrese JM, Levine SS, Yeo GW, Rahl PB, Flynn RA, Young RA, Sharp PA. 2008. Divergent transcription from active promoters. Science 322: 1849-1851.

Shchors K, Evan G. 2007. Tumor angiogenesis: Cause or consequence of cancer? Cancer Res 67: 7059-7061.

Sigova AA, Mullen AC, Molinie B, Gupta S, Orlando DA, Guenther MG, Almada AE, Lin C, Sharp PA, Giallourakis CC, et al. 2013. Divergent transcription of long noncoding RNA/mRNA gene pairs in embryonic stem cells. Proc Natl Acad Sci 110: 2876-2881.

Singh AM, Dalton S. 2009. The cell cycle and Myc intersect with mechanisms that regulate pluripotency and reprogramming. Cell Stem Cell 5: 141-149.

Soufi A, Donahue G, Zaret KS. 2012. Facilitators and impediments of the pluripotency reprogramming factors' initial engagement with the genome. Cell 151: 994-1004.

Sutphin PD, Giaccia AJ, Chan DA. 2007. Energy regulation: HIF MXIes it up with the C-MYC powerhouse. Dev Cell 12: $845-846$.

Takahashi H, Parmely TJ, Sato S, Tomomori-Sato C, Banks CA, Kong SE, Szutorisz H, Swanson SK, Martin-Brown S, Washburn MP, et al. 2011. Human mediator subunit MED26 functions as a docking site for transcription elongation factors. Cell 146: 92-104.

Vander Heiden MG, Locasale JW, Swanson KD, Sharfi H, Heffron GJ, Amador-Noguez D, Christofk HR, Wagner G, Rabinowitz JD, Asara JM, et al. 2010. Evidence for an alternative glycolytic pathway in rapidly proliferating cells. Science 329: 1492-1499.

Van Riggelen J, Yetil A, Felsher DW. 2010. MYC as a regulator of ribosome biogenesis and protein synthesis. Nat Rev Cancer 10: 301-309. 
P.B. Rahl and R.A. Young

Vita M, Henriksson M. 2006. The Myc oncoprotein as a therapeutic target for human cancer. Semin Cancer Biol 16: $318-330$.

Wada T, Takagi T, Yamaguchi Y, Ferdous A, Imai T, Hirose S, Sugimoto S, Yano K, Hartzog GA, Winston F, et al. 1998. DSIF, a novel transcription elongation factor that regulates RNA polymerase II processivity, is composed of human Spt4 and Spt5 homologs. Genes Dev 12: 343-356.

Wang W, Yao X, Huang Y, Hu X, Liu R, Hou D, Chen R, Wang G. 2013. Mediator MED23 regulates basal transcription in vivo via an interaction with P-TEFb. Transcription 4: 39-51.

Whyte WA, Orlando DA, Hnisz D, Abraham BJ, Lin CY, Kagey MH, Rahl PB, Lee TI, Young RA. 2013. Master transcription factors and mediator establish super-enhancers at key cell identity genes. Cell 153: 307-319.

Winkler DD, Luger K. 2011. The histone chaperone FACT: Structural insights and mechanisms for nucleosome reorganization. J Biol Chem 286: 18369-18374.
Wu SY, Lee AY, Lai HT, Zhang H, Chiang CM. 2013. Phospho switch triggers Brd4 chromatin binding and activator recruitment for gene-specific targeting. Mol Cell 49: 843-847.

Yamaguchi Y, Takagi T, Wada T, Yano K, Furuya A, Sugimoto S, Hasegawa J, Handa H. 1999. NELF, a multisubunit complex containing RD, cooperates with DSIF to repress RNA polymerase II elongation. Cell 97: 41-51.

Yang Z, Yik JH, Chen R, He N, Jang MK, Ozato K, Zhou Q. 2005. Recruitment of P-TEFb for stimulation of transcriptional elongation by the bromodomain protein Brd4. Mol Cell 19: 535-545.

Zeitlinger J, Stark A, Kellis M, Hong JW, Nechaev S, Adelman K, Levine M, Young RA. 2007. RNA polymerase stalling at developmental control genes in the Drosophila melanogaster embryo. Nat Genet 39: 1512-1516.

Zhou Q, Li T, Price DH. 2012. RNA polymerase II elongation control. Annu Rev Biochem 81: 119-143. 


\section{$\&_{\mathrm{CSH}}^{\infty} \&$ Cold Spring Harbor

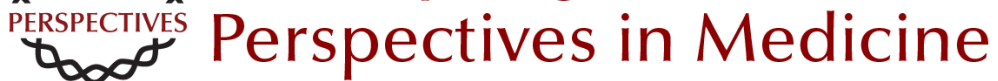

\section{MYC and Transcription Elongation}

Peter B. Rahl and Richard A. Young

Cold Spring Harb Perspect Med 2014; doi: 10.1101/cshperspect.a020990

Subject Collection MYC and the Pathway to Cancer

MYC Cofactors: Molecular Switches Controlling

Diverse Biological Outcomes Stephen R. Hann

MYC Association with Cancer Risk and a New

Model of MYC-Mediated Repression Michael D. Cole

MYC and the Art of MicroRNA Maintenance James N. Psathas and Andrei Thomas-Tikhonenko

MYC Activation Is a Hallmark of Cancer Initiation and Maintenance

Meital Gabay, Yulin Li and Dean W. Felsher

MYC and Mitochondrial Biogenesis Fionnuala Morrish and David Hockenbery

Synthetic Lethal Screens as a Means to

Understand and Treat MYC-Driven Cancers Silvia Cermelli, In Sock Jang, Brady Bernard, et al.

An Overview of MYC and Its Interactome Maralice Conacci-Sorrell, Lisa McFerrin and Robert N. Eisenman

Socializing with MYC: Cell Competition in Development and as a Model for Premalignant Cancer

Laura A. Johnston
MYC and the Control of Apoptosis Steven B. McMahon

Therapeutic Strategies to Inhibit MYC Michael R. McKeown and James E. Bradner

MYC and the Control of DNA Replication David Dominguez-Sola and Jean Gautier

MYC Regulation of Cell Growth through Control of Transcription by RNA Polymerases I and III Kirsteen J. Campbell and Robert J. White

MYC Degradation Amy S. Farrell and Rosalie C. Sears

MYC and Transcription Elongation Peter B. Rahl and Richard A. Young

c-MYC-Induced Genomic Instability Alexandra Kuzyk and Sabine Mai

Oncogenic Mechanisms in Burkitt Lymphoma Roland Schmitz, Michele Ceribelli, Stefania Pittaluga, et al.

For additional articles in this collection, see http://perspectivesinmedicine.cshlp.org/cgi/collection/ 